\title{
Accuracy of Pediatric Risk of Mortality (PRISM) III Score in Predicting Mortality Outcomes in a Pediatric Intensive Care Unit in Karachi
}

\author{
Sadiq Mirza ${ }^{1}$, Laraib Malik ${ }^{2}$, Jawad Ahmed ${ }^{3}$, Farheen Malik ${ }^{3}$, Hassaan Sadiq ${ }^{4}$, Sanower Ali ${ }^{5}$, Sina Aziz ${ }^{6}$ \\ 1. Pediatric Critical Care, The Indus Hospital, Karachi, PAK 2. Pediatrics, Abbasi Shaheed Hospital, Karachi, PAK 3. \\ Internal Medicine, Dow University of Health Sciences, Karachi, PAK 4. Surgery, Civil Hospital, Dow University of Health \\ Sciences, Karachi, PAK 5. Community Health Science, Jinnah Dental and Medical College, Karachi, PAK 6. Pediatrics, \\ Karachi Medical and Dental College, Karachi, PAK
}

Corresponding author: Jawad Ahmed, jawadahmedd13@gmail.com

\section{Abstract \\ Background}

With the advancements in medicine and increasing access to modern technology, pediatric intensive care units (PICU) are becoming a vital part of any health care setting. PICUs play a key role in saving the life of young patients. Various scales have been designed by researchers to aid in predicting the mortality of a patient admitted in PICU. Pediatric Risk of Mortality (PRISM) and Pediatric Index of Mortality (PIM) are among the most commonly used scales. Calculating the risk of mortality enables the physicians to classify the patients and helps in identifying which patients require more urgent care and resources.

\section{Methods}

A hospital-based prospective study was carried out at PICU in a tertiary care hospital in Karachi from December 2017 to June 2019. All patients between the age of one month and 12 years were included in our study after informed consent from parents/guardians. A standard questionnaire was used and the PRISM III score was calculated at 24 hours of admission. All necessary investigations were carried out, and all statistical analyses were carried out using SPSS v.23 (IBM, Armonk, NY).

\section{Results}

A total of 407 patients were included in our study with the majority being males (54.5\%). The mean age was $27 \pm 33$ months. The mean duration of stay of patients in PICU was $80.15 \pm 36.58$ hours. The mortality rate in our study was $37.35 \%(n=152)$. The need for mechanical ventilation, use of inotropic drugs, higher temperatures, and low Glasgow Coma Scale scores were associated with poor survival. It was noted that as the PRISM III score increased, the mortality rate also increased. In our study, we found that PRISM III had good predictive power in our population. The area under the curve was $0.903 \pm 0.016(p<0.001,95 \%$ confidence interval: 0.872-0.934).

Received 03/23/2020

Review began 03/26/2020 Review ended 03/26/2020 Published 03/31/2020

() Copyright 2020

Mirza et al. This is an open access article distributed under the terms of the Creative Commons Attribution License CC-BY 4.0., which permits unrestricted use, distribution, and reproduction in any medium, provided the original author and source are credited.

\section{Conclusions}

PRISM III score showed excellent accuracy and predictive ability in our population. There was no significant difference in observed and expected mortality rates in our study. In a resource-limited setting, the prediction models highlight the cases where more medical attention is required and also enable the physicians to assess the prognosis of the patient so adequate measures can be taken beforehand.

Categories: Emergency Medicine, Pediatrics

Keywords: pediatrics, paediatrics, pediatric mortality, prism, pediatric intensive care unit, picu, emergency medicine, mechanical ventilation, inotropic drugs

\section{Introduction}

The pediatric intensive care units (PICUs) have drastically improved in Pakistan in the last decade. With the availability of specialized life supporting machines and well-trained staff, intensive care units (ICU) are playing a key role in combating life-threatening conditions and illnesses. PICUs work with the fundamental purpose of reducing mortality by intensively monitoring and treating patients with potentially fatal physiological dysfunctions. Estimating the risk of mortality in ICU allows the physicians to assess the prognosis of the patient, plan therapies, and aid in evaluating the performance and resource utilization in an ICU [1-3].

The prediction of mortality risk by pediatricians is highly subjective (qualitative); therefore, there is a need for a scoring system (quantitative) for patients admitted to PICU. Clinical scoring systems have become a vital instrument in ICU. Index of Physiological Stability score (1984) consisting of 34 variables was one of 
the initial scoring systems used in pediatrics [4]. In 1988, Pollack et al. designed Pediatric Risk of Mortality (PRISM) score for prediction of mortality in PICU. It consisted of 14 variables [5]. PRISM was later modified to PRISM III with an addition of three variables by Pollack in 1996. PRISM III (17 variables) was tested among 11,165 patients in 32 PICUs across the USA and yielded better results than PRISM in predicting mortality [6]. Prediction of mortality can be assessed using 12 hours (PRISM III-12) or 24 hours (PRISM III24) data. PRISM III-24 is more accurate for individual patient's mortality prediction, whereas PRISM III-12 is primarily used in qualitative studies [6]. In Europe, the Pediatric Index of Mortality (PIM) consisting of eight variables was put forward by Shann et al. and it was done immediately after admission of the patient $[7]$.

One of the drawbacks of mortality predicting models is that they are population sensitive. A pilot study is necessary before the initiation of their use in any PICU. The PRISM III has been studied with successful results in various PICUs; however, an Italian study carried out in 26 PICUs did not support the predictive power of PRISM III [8-12]. There is only limited data related to the application of PRISM III in tertiary hospitals across Pakistan. This study aimed to evaluate the suitability of PRISM III for our population and to determine the accuracy of the PRISM III score in predicting the mortality outcome of patients admitted in PICU of a tertiary care hospital in Karachi.

\section{Materials And Methods}

\section{Study design and duration}

A prospective hospital-based study was carried out at PICU of Abbasi Shaheed Hospital (ASH) Karachi from December 2017 to June 2019. PICU at ASH comprises of five beds and admits children from one month to 12 years of age.

\section{Study population and inclusion criteria}

The data were collected using a consecutive sampling technique. Critically ill pediatric patients between one month and 12 years of age who were admitted directly to the PICU of our hospital or referred from some other hospitals due to any medical or surgical emergencies were included in our study for one and a half year. Informed consent from the patient's parents/guardian was obtained prior to inclusion in the study.

\section{Exclusion criteria}

Exclusion criteria were defined as follows: (1) all the patients that were $\leqslant 1$ month and >12 years of age, (2) had an underlying malignancy or congenital malformation, and (3) left against medical advice within 24 hours of admission.

\section{Ethical approval}

Ethical approval was obtained from the Ethical and Scientific Review Committee, Karachi Medical \& Dental College (Ref: 007/17, dated April 27, 2017).

\section{Study tool}

On admission and after appropriate consent, a standard PRISM III-24 questionnaire was used for the study patients meeting the inclusion criteria. As per standard medical form, demographic data such as gender, age, diagnosis, nature of outcome (survival/non-survival), and duration of stay in PICU, a requirement of ventilator support, vital monitoring (heart rate, temperature, blood pressure, Glasgow Coma Scale [GCS] score, and pupillary reactions), and lab parameters were filled in for each patient. Laboratory investigations for arterial blood gases parameters, $\mathrm{pH}$, and levels of glucose, potassium, creatinine, blood urea nitrogen, and liver function tests were carried out. A complete history, thorough physical examination, and appropriate laboratory investigations were carried out for each patient.

\section{Statistical analysis}

All the data were pooled into Statistical Package for Social Science (SPSS) software version 23.0 (IBM, Armonk, NY) and all the analyses were carried out through it. Continuous variables such as weight, age, and length of PICU stay were reported as means or medians with standard deviations. T-test and chi-square tests were used to find any relation between different variables. The receiver operating characteristics (ROC) curve was plotted to find the sensitivity and specificity of PRISM III. The Hosmer and Lemeshow goodness-of-fit chi-square test was carried out to see the goodness of the predictive model.

Data were collected, and the PRISM III score was calculated within 24 hours of admission at PICU. The PRISM III score evaluation was done as per the recommendation of Pollack et al. [6]. The outcome was calculated from the total score achieved by each patient as survivors versus non-survivor.

\section{Results}




\section{Cureus}

A total of consecutive 572 patients were approached for the study, and of these 407 (54.5\% boys/45.5\% girls) were included in our study. The rest of the patients were not analyzed based on exclusion criteria or insufficient data. The mean age and weight of the participants were $27 \pm 33$ months and $10.20 \pm 7.94 \mathrm{~kg}$, respectively. The mean duration of PICU stay was $80.15 \pm 36.58$ hours. Study characteristics and different presenting diseases are displayed in Table 1 and Table 2 , respectively.

\begin{tabular}{|c|c|c|}
\hline Variables & $\mathrm{N}(\%)$ & P-value \\
\hline Total patients & 407 & \\
\hline Gender & & 0.067 \\
\hline Males & $222(54.5)$ & \\
\hline Females & $185(45.5)$ & \\
\hline \multicolumn{3}{|l|}{ Age (months) } \\
\hline$>1-12$ & 239 (58.72) & \\
\hline$>12-60$ & $108(26.54)$ & \\
\hline$>60-120$ & 60 (14.74) & \\
\hline$>120$ & $0(0)$ & \\
\hline Mean age (months) & $27 \pm 33$ & 0.075 \\
\hline Median age (months) & $9 \pm 33$ & 0.075 \\
\hline Mean weight (kg) & $10.20 \pm 7.94$ & 0.342 \\
\hline Mean PICU stay (hours) & $80.15 \pm 36.58$ & 0.087 \\
\hline Temperature $<33$ or $<40^{\circ} \mathrm{C}$ & $7(1.7)$ & 0.008 \\
\hline GCS score & & $<0.0001$ \\
\hline More than 8 & $322(79.1)$ & \\
\hline Less than 8 & $85(20.9)$ & \\
\hline Mechanical ventilation & & 0.009 \\
\hline Yes & $143(35.2)$ & \\
\hline No & $264(64.9)$ & \\
\hline Inotropic drugs & & 0.005 \\
\hline Yes & $160(39.4)$ & \\
\hline No & $247(60.6)$ & \\
\hline \multicolumn{3}{|l|}{ Outcome } \\
\hline Survived & 255 (62.65) & \\
\hline Expired & $152(37.4$ & \\
\hline
\end{tabular}

TABLE 1: Demographic profile of the study.

P-value shows the association of the variables with mortality outcome.

PICU, pediatric intensive care unit; GCS, Glasgow Coma Scale. 


\section{Cureus}

\begin{tabular}{|c|c|c|}
\hline Diagnosis & $\mathbf{N}(\%)$ & $\begin{array}{l}\text { Mortality } \\
(\%)\end{array}$ \\
\hline Acute exacerbation of asthma & $24(5.9)$ & $3(12.5)$ \\
\hline Bronchiolitis & $72(17.7)$ & $11(15.3)$ \\
\hline Encephalitis (bacterial or fungal) & $29(7.1)$ & $239(79.3)$ \\
\hline Enteric fever with complications & $3(0.7)$ & $1(33.3)$ \\
\hline Guillain-Barré syndrome & $6(1.6)$ & $4(66.7)$ \\
\hline Measles with complications (including encephalitis or pneumonia) & $42(10.3)$ & $27(64.3)$ \\
\hline IMieningitis & $\begin{array}{l}101 \\
(24.8)\end{array}$ & $47(46.5)$ \\
\hline Pneumonia & $83(20.4)$ & $14(16.9)$ \\
\hline Poisoning & $14(3.4)$ & $6(42.9)$ \\
\hline Post measles encephalitis & $8(2.0)$ & $6(75)$ \\
\hline Sepsis & $16(3.9)$ & $7(43.8)$ \\
\hline $\begin{array}{l}\text { SCD, status epileptics, TB with effusion, thalassemia, AFP (polio), CLD, CF, pneumothorax, and head } \\
\text { trauma* }\end{array}$ & $9(2.21)$ & $3(33.3)$ \\
\hline Total & 407 & 152 \\
\hline
\end{tabular}

\section{TABLE 2: Presenting diseases and the distribution of mortality rates.}

SCD, sickle cell disease; TB, tuberculosis; AFP, acute flaccid paralysis; CLD, chronic liver disease; CF, cystic fibrosis

*Each case had an incidence of $n=1$.

\section{Mortality and variables}

Out of the 407 patients, 152 died (non-survivors) in PICU and 255 survived. The overall mortality rate was $37.35 \%$. No significant association was found between gender, age, and length of PICU stay of the patient with the mortality outcome ( $\mathrm{p}=0.067, \mathrm{p}=0.075$, and $\mathrm{p}=0.087$ respectively). Need for mechanical ventilation $(\mathrm{p}=0.009)$, use of inotropic drugs $(\mathrm{p}=0.005)$, higher temperature $(\mathrm{p}=0.008)$, and low GCS $(\mathrm{p}<0.0001)$ were associated with poor outcome. A significant association was noted between mortality outcome with systolic blood pressure $(\mathrm{p}<0.0001)$ and pupillary reflex $(\mathrm{p}<0.0001)$, while no association was observed for heart rate $(\mathrm{p}=0.432)$ and $\mathrm{pH}(\mathrm{p}=0.79)$.

\section{PRISM III score and mortality}

A significant association was found between the PRISM III score and mortality outcome $(p<0.001)$. The mean PRISM III score was $8.32 \pm 7.07$. A total of 291 patients had a score of $<10$ and the mortality rate among them was $13.75 \%$. Among 62 patients who had a score of 10 to $19,93.54 \%$ of patients expired and only $6.46 \%$ of patients survived. The mortality rate was $100 \%$ in patients who had a score of $>20$. As the PRISM III score increased, the rate of mortality also increased. A more detailed distribution of PRISM III score with mortality rate is shown in Figure 1. 


\section{Cureus}

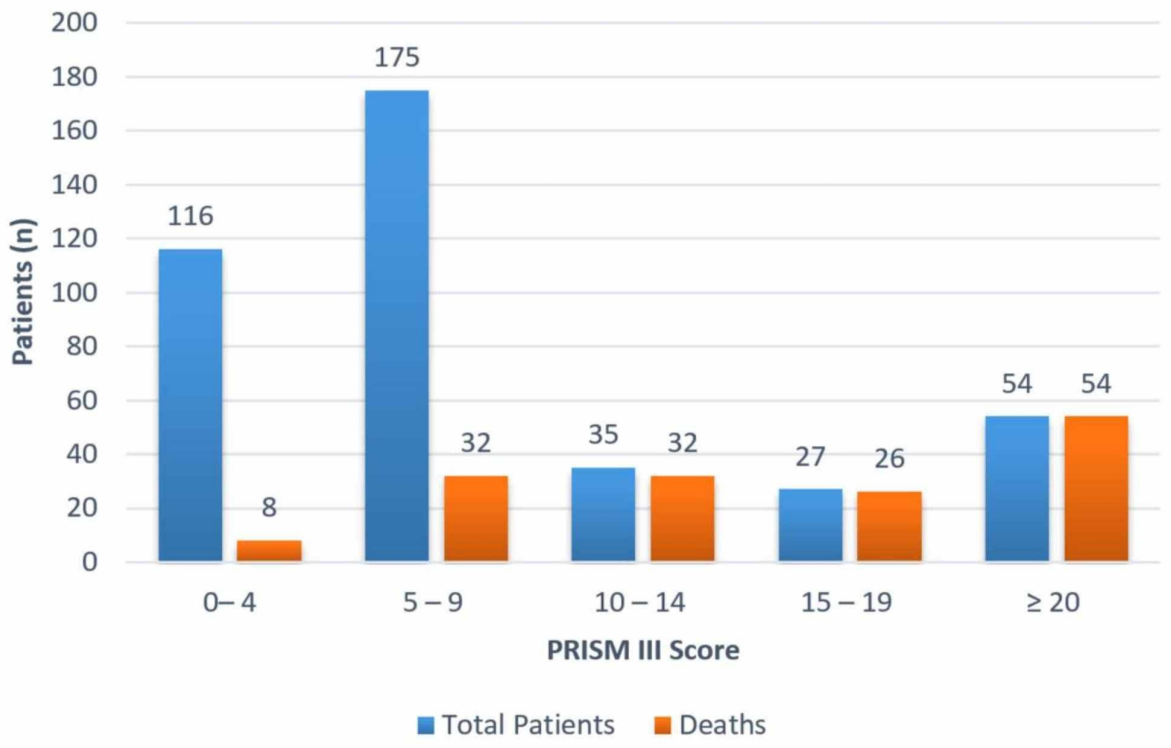

FIGURE 1: Distribution of mortality according to PRISM III score.

PRISM, Pediatric Risk of Mortality.

\section{Goodness of prediction of PRISM III}

The predicted mortality rate by the PRISM III scores correlated well with the actual observed mortality rate as shown in Table 3. The Hosmer and Lemeshow goodness-of-fit chi-square test was used to appreciate the goodness of prediction. The result showed that the expected mortality rate was $37.7 \%$ and the observed mortality rate in our study was $37.4 \%$. No significant difference was seen between the expected and observed mortality rate $(\mathrm{p}=0.631)$. A $\mathrm{p}$-value of $>0.05$ is considered good suitability of the test.

\begin{tabular}{|c|c|c|c|c|c|}
\hline \multirow{2}{*}{ PRISM III score } & \multirow{2}{*}{ Total } & \multicolumn{2}{|l|}{ Survival } & \multicolumn{2}{|l|}{ Expired } \\
\hline & & Observed & Expected & Observed & Expected \\
\hline $0-4$ & 116 & 108 & 107.82 & 8 & 8.09 \\
\hline $5-9$ & 175 & 143 & 142.30 & 32 & 32.77 \\
\hline 10-14 & 35 & 03 & 3.11 & 32 & 31.86 \\
\hline $15-19$ & 27 & 01 & 0.83 & 26 & 24.91 \\
\hline$\geq 20$ & 54 & 00 & 0.05 & 54 & 55.69 \\
\hline Total & 407 & 255 & 254.11 & 152 & 153.32 \\
\hline
\end{tabular}

TABLE 3: Goodness of the predictive model by the Hosmer and Lemeshow chi-square test.

PRISM, Pediatric Risk of Mortality.

\section{Accuracy of prediction of PRISM III}

PRISM III scores offered a good discriminative power in our center with 0.903 (95\% CI) area under the ROC curve (Figure 2). The area under the curve is a measure of the overall accuracy of the model as well as its ability to predict mortality. The closer the area under the ROC curve is to 1.0 , the more accurate the model. Taking 10 as cut-off point, the sensitivity and specificity of PRISM III model in our population were $73.7 \%$ and $98.4 \%$, respectively. 


\section{Cureus}

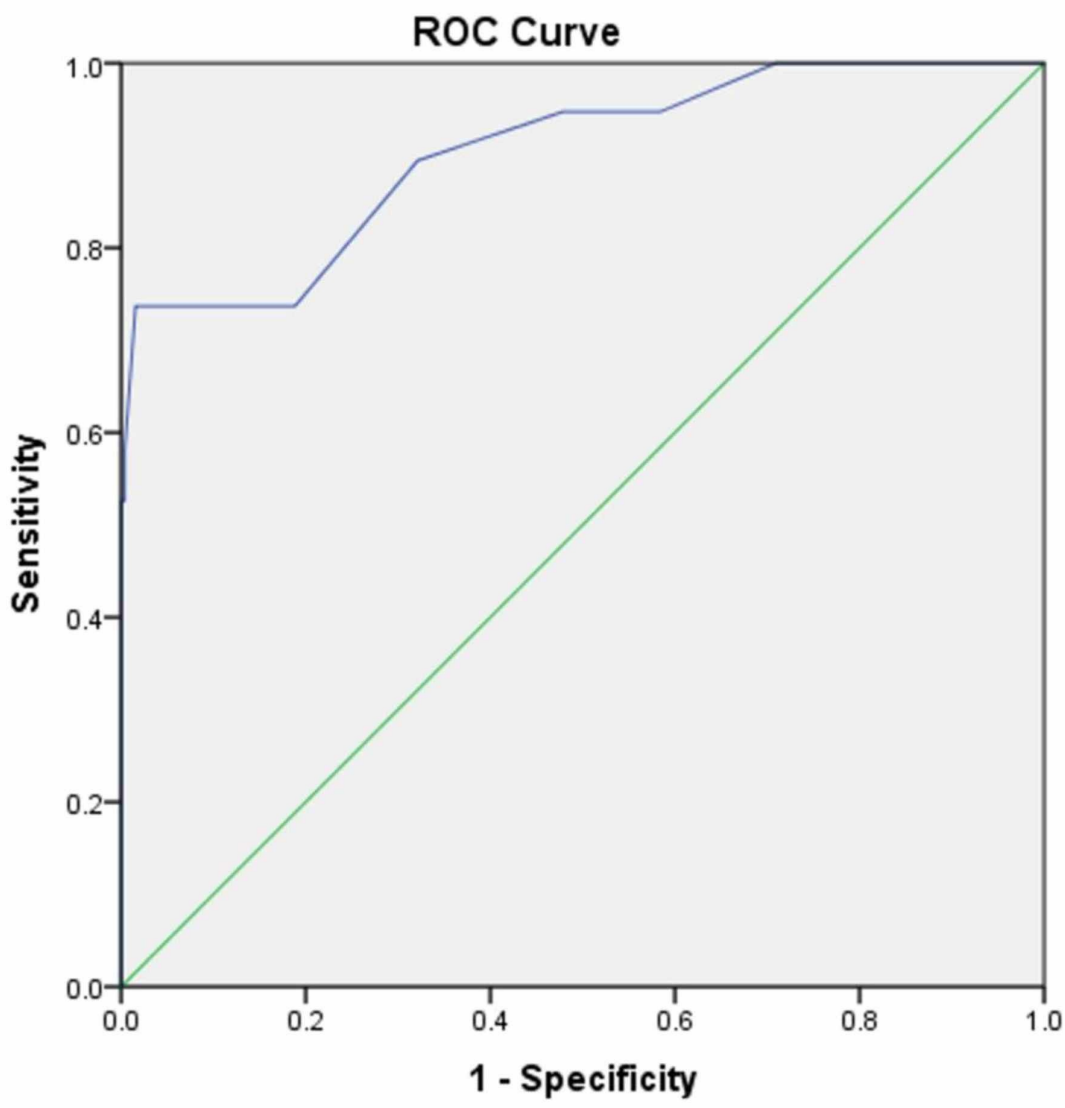

Diagonal segments are produced by ties.

\section{FIGURE 2: ROC curve for PRISM III score.}

Area under the curve is $0.903 \pm 0.016(p<0.001,95 \% \mathrm{Cl}: 0.872-0.934)$.

ROC, receiver operating characteristics; PRISM, Pediatric Risk of Mortality; Cl, confidence interval.

\section{Discussion}

Prediction models of mortality provide great insight to health care administrators regarding the prognosis of the patient and may greatly benefit the decision process as well as the outcome of the patient.

A variety of models exist for the prediction of mortality in patients of PICU, including the Pediatric Risk of Mortality (PRISM, PRISM III) and the Pediatric Index of Mortality (PIM and PIM 2) [5,7,13]. Regardless, globally the PRISM III score is used more frequently and we decided to utilize it as well. Although these prediction models are an asset to intensive care, it is essential to validate them before applying in an environment significantly dissimilar from where they were initially developed. The purpose of this study was to use a critical illness scoring system like PRISM-III to assess the mortality risk and its validity in predicting the outcome of patients admitted to PICU at a tertiary care hospital with resource-limited settings.

The findings from this study elucidate that the mortality rate predicted by the PRISM III score correlated well with the actual observed mortality rate, thus providing an accurate estimate of the prognosis and outcome of the patients admitted in PICU.

In this study, the observed mortality rate was $37.35 \%$. This mortality is significantly higher when compared to comparable studies carried out in developing countries $[9,14,15]$. This highlights the need for better resource allocations and practices in the PICU in our country. A directly proportional relationship was noted between the PRISM III score and the mortality, that is as the PRISM III score increases, mortality rate also increases. This finding was similar to researches carried out in India, Hong Kong, and the UK $[9,16,17]$. In most of the studies done previously, the primary illness is usually due to trauma, hereditary disease, or malignancies. Conversely, in our study population, communicable and infectious diseases like meningitis (24.8\%) and pneumonia (20.4\%) were more common. This was concordant with a previous study done in Pakistan [15]. 
The distribution of gender in our research was analogous to previous studies carried out in the nearby region, but no significant association was seen between gender and mortality $[15,18]$. This finding was comparable to previous work done in Brazil and Nepal [14,19]. In contrast, Aragao et al. discovered in his study population that males had a greater risk of mortality than females [20]. Our patients were considerably younger (median age, nine months) in comparison to the study done originally by Pollak et al. to validate PRISM, which was 33 months [5]. We further observed that the use of inotropic drugs $(\mathrm{p}=0.005)$ and mechanical ventilation ( $\mathrm{p}=0.009$ ) were considered risk factors for mortality, which was consistent with other studies where procedures like these were considered high risk for the pediatric patients [14,19].

PRISM III-24 contains 17 physiological variables. These variables include but are not limited to systolic blood pressure, mental status, heart rate, and glucose. A significant association between these physiologic variables and mortality outcome has been uneven across the literature as elucidated by Table 4 . This table compares different variables in our study with other research studies reported worldwide.

\begin{tabular}{|c|c|c|c|c|c|c|c|}
\hline Study name & Location & $\begin{array}{l}\text { Mortality outcome } \\
(\%)\end{array}$ & GCS score & Systolic BP & Heart rate & $\begin{array}{l}\text { Pupillary } \\
\text { reflexes }\end{array}$ & $\mathrm{pH}$ \\
\hline Our study & Pakistan & 37.35 & Significant & Significant & $\begin{array}{l}\text { Non- } \\
\text { significant }\end{array}$ & Significant & $\begin{array}{l}\text { Non- } \\
\text { significant }\end{array}$ \\
\hline Varma et al [9] & India & 14.8 & Significant & Significant & $\begin{array}{l}\text { Non- } \\
\text { significant }\end{array}$ & Significant & Significant \\
\hline $\begin{array}{l}\text { Ana Lilia et al } \\
\text { [8] }\end{array}$ & Mexico & 24.7 & $\begin{array}{l}\text { Non- } \\
\text { significant }\end{array}$ & $\begin{array}{l}\text { Non- } \\
\text { significant }\end{array}$ & $\begin{array}{l}\text { Non- } \\
\text { significant }\end{array}$ & Significant & Significant \\
\hline $\begin{array}{l}\text { Pollack et al } \\
\text { [6] }\end{array}$ & USA & 2.2 to 16.4 & Significant & Significant & $\begin{array}{l}\text { Non- } \\
\text { significant }\end{array}$ & Significant & $\begin{array}{l}\text { Non- } \\
\text { significant }\end{array}$ \\
\hline
\end{tabular}

TABLE 4: Comparision of the significance of physiologic variables among different studies.

GCS, Glasgow Coma Scale; BP, blood pressure.

Scoring models suggest that a discriminatory power of 0.90 and above is deemed excellent, 0.80 to 0.89 to be good, and 0.70 to 0.79 to be fairly suitable $[21,22]$. Furthermore, the predictive ability of a model can be assessed by estimating how close the ROC curve is to 1.0. The present study demonstrates that PRISM III acts as an excellent discriminative tool (0.903 area under the ROC curve). Previous studies conducted in Pakistan have yielded similar results to ours. Siddique et al. and Quereshi et al. demonstrated PRISM to have a good discriminative and predictive ability with an area under the ROC curve of 0.885 and 0.78 ,

respectively $[15,18]$. Choi et al. reported that the area under the ROC curve for PRISM was 0.910 and was an excellent predictor of mortality in intensive care settings [16]. Studies that were carried out in Iran and India also observed a good discriminative ability of PRISM with an area under the ROC curve to be greater than 0.8 and 0.86 , respectively $[9,23]$.

Our study incorporated a variety of patients with different illnesses which shows that the PRISM III was suitable for varying morbidities. The other strength of our study was a large sample size which made our results more robust. However, our study was limited by the fact that it was a single-center study. Caution has to be taken before generalizing the results for the population of various areas where resources are more limited. A wider study needs to be conducted that encompasses hospitals from different cities of Pakistan.

\section{Conclusions}

PRISM III was found to be an excellent predictor of mortality in our population. Factors such as mechanical ventilation, inotropic drugs use, and low GCS scores were associated with poor outcomes. More than half of our presenting population was younger than one year, and infectious causes were the main reason for admission in most of the cases. Using the prediction models, physicians can assess the survival chances of the patient. In settings where there is a shortage of medicines and staff, such models enable physicians to decide how and where to direct their limited resources.

\section{Additional Information \\ Disclosures}

Human subjects: Consent was obtained by all participants in this study. Ethical and Scientific Review 
Committee, Karachi Medical \& Dental College issued approval Ref: 007/17, dated April 27, 2017. Full approval for the study has been granted by Ethical and Scientific Review Committee, Karachi Medical \& Dental College for this research. . Animal subjects: All authors have confirmed that this study did not involve animal subjects or tissue. Conflicts of interest: In compliance with the ICMJE uniform disclosure form, all authors declare the following: Payment/services info: All authors have declared that no financial support was received from any organization for the submitted work. Financial relationships: All authors have declared that they have no financial relationships at present or within the previous three years with any organizations that might have an interest in the submitted work. Other relationships: All authors have declared that there are no other relationships or activities that could appear to have influenced the submitted work.

\section{References}

1. Keene AR, Cullen DI: Therapeutic intervention scoring system: update 1983. Crit Care Med. 1983, 11:1-3.

2. Pollack MM, Ruttimann UE, Getson PR: Accurate prediction of the outcome of pediatric intensive care. N Engl J Med. 1987, 316:134-139. 10.1056/NEJM198701153160304

3. Pollack MM, Ruttimann UE, Glass NL, Yeh TS: Monitoring patients in pediatric intensive care. Pediatrics. 1985, 76:719-724.

4. Yeh TS, Pollack MM, Ruttimann UE, Holbrook PR, Fields AI: Validation of a physiologic stability index for use in critically ill infants and children. Pediatr Res. 1984, 18:445-451. 10.1203/00006450-198405000-00011

5. Pollack MM, Ruttimann UE, Getson PR: Pediatric Risk of Mortality (PRISM) score . Crit Care Med. 1988, 16:1110-1116. 10.1097/00003246-198811000-00006

6. Pollack MM, Patel KM, Ruttimann UE: PRISM III: an updated pediatric risk of mortality score . Crit Care Med. 1996, 24:743-527. 10.1097/00003246-199605000-00004

7. Shann F, Pearson G, Slater A, Wilkinson K: Paediatric index mortality (PIM): a mortality prediction model for children in intensive care. Intensive Care Med. 1997, 23:201-207. 10.1007/s001340050317

8. De León AL, Romero-Gutiérrez G, Valenzuela CA, González-Bravo FE: Simplified PRISM III score and outcome in the pediatric intensive care unit. Pediatr Int. 2005, 47:80-83. 10.1111/j.1442-200x.2004.01997.x

9. Varma A, Damke S, Meshram R, Vagha J, Kher A, Vagha K: Prediction of mortality by pediatric risk of mortality (PRISM III) score in teriary care rural hospital in India. Int J Contemp Pediatr. 2017, 4:322-331. 10.18203/2349-3291.ijcp20170003

10. Wang JN, Wu JM, Chen YJ: Validity of the updated pediatric risk of mortality score (PRISM III) in predicting the probability of mortality in a pediatric intensive care unit. Acta Paediatr Taiwan. 2001, 42:333-337.

11. Volakli EM, Mantzafleri PE, Sdougka M: Pediatric risk of mortality (PRISM III-24) performance in a Greek pediatric intensive care unit. The Greek E-Journal of Perioperative Medicine. 2013, 11:31-43. Accessed: March 15, 2020: https://e-journal.gr/pediatric-risk-of-mortality-prism-iii-24-performance-in-a-greekpediatric-intensive-care-unit/.

12. Bertolini G, Ripamonti D, Cattaneo A, Apolone G: Pediatric risk of mortality: an assessment of its performance in a sample of 26 Italian intensive care units. Crit Care Med. 1998, 26:1427-1432. 10.1097/00003246-199808000-00031

13. Slater A, Shann F, Pearson G: PIM2: a revised version of the pediatric index of mortality . Intensive Care Med. 2003, 29:278-285. 10.1007/s00134-002-1601-2

14. Bora R: Prediction of mortality by pediatric risk of mortality (PRISM) III score In NGMC pediatric intensive care unit. JNGMC. 2019, 17:5-9. 10.3126/jngmc.v17i1.25305

15. Siddique AW, Basheer F, Subhani FA, Meraj H, Naseem S: Mortality risk assessment in pediatric intensive care unit of a developing country using prism score. Pak Armed Forces Med J. 2019, 69:690-695.

16. Choi KM, Ng DK, Wong SF, et al.: Assessment of the pediatric index of mortality (PIM) and the pediatric risk of mortality (PRISM) III score for prediction of mortality in a pediatric intensive care unit in Hong Kong. Hong Kong Med J. 2005, 11:97-103.

17. Brady AR, Harrison D, Black S, et al.: Assessment and optimization of mortality prediction tools for admissions to pediatric intensive care in the United kingdom. Pediatrics. 2006, 117:733-742. 10.1542/peds.2005-1853

18. Qureshi AU, Ali AS, Ahmad TM: Comparison of three prognostic scores (PRISM, PELOD and PIM 2) at pediatric intensive care unit under Pakistani circumstances. J Ayub Med Coll Abbottabad. 2007, 19:49-53.

19. Costa GA, Delgado AF, Ferraro A, Okay TS: Application of the pediatric risk of mortality (PRISM) score and determination of mortality risk factors in a tertiary pediatric intensive care unit. Clinics. 2010, 65:10871092. 10.1590/s1807-59322010001100005

20. Araga o RCF, Albuquerque MFPM, Mello MJG, Ximenes RAA : Risk factors associated with death in children admitted to a paediatric intensive care unit. J Trop Pediatr. 2001, 47:86-91. 10.1093/tropej/47.2.86

21. Yeh TS, Pollack MM, Holbrook PR, Fields AI, Ruttiman U: Assessment of pediatric intensive care: application of the therapeutic intervention scoring system. Crit Care Med. 1982, 10:497-500.

22. Hanley JA, McNeil BJ: The meaning and use of the area under a receiver operating characteristic (ROC) curve. Radiology. 1982, 143:29-36. 10.1148/radiology.143.1.7063747

23. Khajeh A, Noori NM, Reisi M, Fayyazi A, Mohammadi M, Miri-Aliabad G: Mortality risk prediction by application of pediatric risk of mortality scoring system in pediatric intensive care unit. Iran J Pediatr. 2013, $23: 546-550$. 